\section{Aeromonas hydrophila fulminant pneumonia in a fit young man}

\author{
J Rosal Gonçalves, Gabriela Brum, \\ Afonso Fernandes, Isabel Biscaia, \\ Maria José Salvado Correia, \\ Joaquim Bastardo
}

\begin{abstract}
A previously healthy 24 year old athletic man became ill suddenly with pneumonia the day after swimming in the sea. Despite intensive support measures in the intensive care unit he died three hours after admission and 21 hours after his first symptom. Necropsy showed bilateral haemorrhagic necrotising pneumonia. Aeromonas hydrophila was isolated from a blood culture taken at admission and from the lungs at necropsy. The infection may have come from contaminated sea water.
\end{abstract}

Aeromonas hydrophila is an anaerobic Gram negative bacillus that commonly inhabits soil and fresh water. It has been regarded as an opportunist agent as most cases of infection have occurred in immunologically compromised hosts. Infections in apparently healthy people have been described recently, however. The range of infections attributed to this microorganism is large but pneumonia has been rare. ${ }^{1-3}$

We describe fulminating aeromonas hydrophila pneumonia in a previously fit young man.

\section{Case report}

A 24 year old man was admitted to the intensive care unit in severe respiratory distress. He had been in good health but became ill suddenly 18 hours before admission with severe right pleuritic chest pain, cough with small haemoptyses, fever, and increasing shortness of breath. He had swum in the sea 24 hours before he became ill. He had no unusual social or epidemiological history.

On admission he was an alert, muscular young man with severe dyspnoea and cyanosis. His temperature was $37.8^{\circ} \mathrm{C}$, respiratory rate $35 / \mathrm{min}$, pulse 120 beats $/ \mathrm{min}$, and blood pressure $80 / 40 \mathrm{~mm} \mathrm{Hg}$. There were no skin lesions. Clinical and radiographic examination of the chest showed consolidation of the right upper lobe.

The packed cell volume was 0.52 , white blood cell count $9.4 \times 10^{9} / 1$, and platelet count $24.5 \times 10^{9} / 1$. He was serum negative for HIV-I and HIV-II. His arterial oxygen $\left(\mathrm{PaO}_{2}\right)$ and carbon dioxide $\left(\mathrm{PaCO}_{2}\right)$ tensions when he was breathing air were 6.7 and $3.6 \mathrm{kPa}$; the $\mathrm{pH}$ was 7.38. Intensive medical support, including assisted ventilation, was begun but his arterial blood gas tensions continued to deteriorate. After two hours of intensive medical aid he coughed up about $15 \mathrm{ml}$ of bright red blood, became severely shocked, and despite intensive medical efforts died three hours after admission.

At necropsy the lungs were heavy, the left lung weighing $790 \mathrm{~g}$ and the right $870 \mathrm{~g}$. The right lung was uniformly and diffusely solid and the left lung had multiple confluent foci. Microscopically there was vascular engorgement and the alveoli were flooded with erythrocytes and mononuclear and granular leucocytes. Zones of necrosis and haemorrhage were present. Many small Gram negative bacilli were seen in both lungs, especially in the areas of necrosis. Other organs were normal apart from generalised congestion.

An organism recovered from blood was cultured on a brain-heart infusion at $37^{\circ} \mathrm{C}$ after 24 hours and one from a necropsy sample of the lung after plating on to blood agar and McConkey agar and overnight incubation at $37^{\circ} \mathrm{C}$. It was provisionally identified as Aeromonas sp on the basis of aerobic growth of a Gram negative rod, being oxidase and catalase positive and showed $\beta$ haemolysis of blood agar. Its final identification as $A$ hydrophila was confirmed by the API 20 NE technique (API System), isolates from the two sources having the same biochemical profiles.

Antibiotic sensitivity testing was performed by the comparative disc diffusion method ${ }^{4}$ on DST agar at $37^{\circ} \mathrm{C}$. The organism was resistant to ampicillin, carbenicillin, and cephalothin and sensitive to gentamicin, amikacin, cefuroxime, and co-trimoxazole.

\section{Discussion}

Aeromonas hydrophila is an anaerobic Gram negative bacillus found primarily in fresh water and soil habitats. Human infections with this agent are usually due to exposure to contaminated water. Their origin can, however, be endogenous, coming from the intestine. It was initially believed that Aeromonas was basically an oportunist agent, but infections in apparently healthy people have been described recently, including meningitis, ${ }^{5-7}$ arthritis, ${ }^{8}$ and pulmonary ${ }^{9}$ and hepatic abscess. ${ }^{7}$ Septicaemia is a frequent complication.

$A$ hydrophila pneumonia is quite rare. Of the 12 published cases, ${ }^{1-3} 10$ occurred in men. Predisposing factors were found in all but three of the cases. In eight the infection was attributed to near drowning in contaminated water. The acute infection was fatal in five subjects. Nosocomial infections caused by $A$ hydrophila have also been described. ${ }^{10}$ No predisposing factor was identified in our patient, the only relevant factor being his recent swim in the sea. Although $A$ hydrophila is not considered a marine bacterium, it is tolerant to sodium chloride and to tem- 
peratures from $4^{\circ}$ to $45^{\circ} \mathrm{C}$, and is able to survive in sea water. This seems the most probable environmental source for this case.

Laboratories should be altered to the possibility of $A$ hydrophila as a potential pathogenic organism. Treatment with aminoglycosides and vigorous pulmonary and cardiovascular support is required. Clinicians should be aware of the virulence of this rare organism.

1 Baddourr LM, Baselski VS. Pneumonia due to Aeromonas hydrophila complex: epidemiologic clinical and microbiologic features. South Med J 1988;81:461-3.

2 Reines HD, Cook FV. Pneumonia and bacteremia due to Aeromonas hydrophila. Chest 1981;80:264-7.

3 Scott EG, Russell CM, Noel KT, Sproul AE. Aeromonas hydrophila sepsis in a previously healthy man. JAMA 1978;239:1742.
4 Waterworth PM. Laboratory control. In: Garrod LP, Lambert HP, Grady FO, eds. Antibiotic and chemotherapy. 5th ed. Edinburgh: Churchill Livingstone, 1981: 464-504.

5 Ellison RT, Mostow SR. Pyogenic meningitis manifesting during therapy for Aeromonas hydrophila sepsis. Arch Intern Med 1984;144:2078-9.

6 Dahm LJ, Weinberg AG. Plesiomonas (Aeromonas) shigelloides septicemia and meningitis in a neonate. South Med J 1980;73:393-4.

7 Yadava R, Seeler RA, Kalelkar M, Royal JE. Fatal Aeromonas hydrophila sepsis and meningitis in a child with sickle cell anemia. Am J Dis Child 1979;133:753-4.

8 Master R, Weisman MH, Armbuster TG, Slivka J, Resnick $\mathrm{D}$, Goerger TG. Sepsis arthritis of the glenohumeral joint. Unique clinical and radiographic festures and a favourable outcome. Arthr Rheum 1977;20:1500-6.

9 Gaussorgner P, Bachmann P, Tigand S, Piperno D, Jaboulay JM, Salord F, et al. Abces pulmonaire a Aeromonas hydrophila: complication de noyade en eau douce. Ann Med Intern 1987;138:666-7.

10 Plotkin GR, Scinico MW. Nosocomial pneumonia due to $A$ hydrophila. Pathol Med 1986;89:40-2.

\section{Little Old New York}

Having long since acquired the trappings of a backwoodsman, I sometimes contemplate with pleasure 1938. That was the year in which, aged 28 and fresh from a general medical registrarship, I sailed to New York with a view to furthering my knowledge of chest medicine. By good fortune, I was introduced to two of the most distinguished members of our specialtynamely, Dr Eugene Opie, professor of pathology at New York Hospital, and Professor J Burns Amberson of Bellevue Hospital, perhaps the best known chest physician at that time.

Reporting to Dr Opie, I was soon immersed in controversies over natural and acquired immunity and resistance to tuberculosis in various animal species, a subject on which a dozen or so doctors were working in his department. I was set the task of tracing the fate of tubercle bacilli after their intravenous injection into rats. I will never forget the occasion when a laboratory assistant called $\mathrm{Mr}$ Lardy dumped a large toffee tin on my bench containing 20-30 albino rats each weighing about 150 grams. With his aid in anaesthetising and holding them down, I made a nick in the groin and injected a measured dose of bacilli into the saphenous (or was it the femoral?) vein. To this day I believe that the veins were smaller than the needles I was required to insert, but with practice I became proficient. These and other tins of rats were killed at intervals from half an hour to six months and the numbers of bacilli in their lungs and elsewhere were counted. With the aid of Dr Opie, an article eventually appeared in the Archives of Pathology.

Soon after my arrival I was shown some radiographs of the chest of macacus rhesus monkeys with massive tuberculous hilar lymph nodes. Having commented that the films were all overexposed, I was delegated to radiograph up to 20 of them twice a week. In time, I learnt the technique of extracting them from their cages without being nipped and then carrying them, one in each hand with their arms behind their backs, to the obsolescent $x$ ray machine. With the monkeys breathing at 50-60 times a minute in short bursts and the machine needing an exposure of at least half a second, good timing was essential. I think I convinced the pathologists who had infected the monkeys that my films were an improvement.

Three times a week I had the privilege of joining the small group accompanying $\mathrm{Dr}$ Amberson on his ward rounds. It was an unforgettable experience. Quite apart from the clinical aspect, there was the sight of a busy city hospital with beds down the centre of the wards and along the corridors and much coming and going. After a particularly noisy distribution of newspapers during one round, Dr Amberson pointed out that the paperman possessed a quality that Sir William Osler insisted all good physicians should possess-namely, imperturbability. It seemed to me to be a desirable quality in anyone wishing to survive the hubbub of Bellevue and one that Dr Amberson possessed in good measure.

Some years later, on my next visit to New York, I called on Dr Opie and said I felt a little guilty that he had made possible such a splendid year and I had given so little in return. He pointed out that he had always welcomed postgraduates who were properly recommended, that his assistants covered a wide range of seniority, and that he tried to ensure that each one was given a task appropriate to his ability.

Is it fair for a clinician to burst into a scientific department and stay for only a year? Dr Opie seemed to think that it was. Maybe I provided a useful pair of hands in his overall study of immunity in tuberculosis and at the same time used my research fellowship profitably. Whatever the answer may be, the experience I gained in scientific methods in what was then affectionately called Little Old New York profoundly influenced my approach to clinical medicine.-NEVILLE C OSWALD 